\title{
EL AMPARO CONSTITUCIONAL EN LA REPÚBLICA DE VENEZUELA: ANTECEDENTES Y EVOLUCIÓN
}

JUAN MANUEL GOIG MARTINEZZ 


\section{SUMARIO}

I. Evolución del amparo desde la independenCla de España hasta la Constitución venezolana de 1961. - II. El amparo en la Constitución dE 1961.- - III. DesarRollo del amparo hasta la PROMULGaCIÓN DE LA Ley Orgánica de Amparo.-1. Confusiones doctrinales y jurisprudenciales.-2. Restricción jurisprudencial del amparo.3. Cambio de criterio de la Corte Suprema: Bases para la admisión de la acción de amparo.-IV. LA LeY ORGÁNICA DE AMPARO ante el Congreso venezolano.-1. El proceso de formación.2. Condicionamientos ideológicos de la regulación del amparo.-3. Propósito y estructura de la Ley Orgánica de Amparo. 
Revista de Derecho Político, núm. 39, 1995, pp. 405-423

\section{EL AMPARO CONSTITUCIONAL EN LA REPÚBLICA DE VENEZUELA: ANTECEDENTES Y EVOLUCIÓN}

POR

JUAN MANUEL GOIG MARTINNEZ

El establecimiento del amparo en Venezuela, entendiendo el amparo en su sentido estricto de instrumento de defensa de los derechos y libertades, se ha producido recientemente en el ordenamiento constitucional venezolano, y con mayor precisión en el artículo 49 de la vigente Constitución de 23 de enero de 1961; no obstante, esto no significa que se haya incluido sorpresivamente en el citado texto ni que haya sido el primer intento en el Derecho venezolano, ya que el reconocimiento del amparo ha supuesto la culminación de una serie de ensayos anteriores destinados a la consagración de un instrumento tutelar de los derechos y garantías reconocidos en el ordenamiento constitucional.

\section{EVOLUCIÓN DEL AMPARO DESDE LA INDEPENDENCIA DE ESPAÑA HASTA LA CONSTITUCIÓN VENEZOLANA DE 1961}

La configuración político-constitucional del Estado en Venezuela se ha producido a través de un largo proceso, de más de siglo y medio, período que separa a Venezuela de la ruptura política con España, durante el cual el Estado venezolano ha estado regido formalmente por 25 textos constitucionales, aunque este elevado número de textos constitucionales no significa, sin embargo, que hayan existido, desde el punto de vista jurídico, y estrictamente hablando, 25 Constituciones, puesto que la mayoría de estos textos han sido enmiendas o reformas parciales de los precedentes, provocadas, en su mayor parte, por factores circunstancia- 
les del ejercicio del poder, que no han tenido una especial incidencia sobre aspectos sustanciales del hilo constitucional '.

La evolución constitucional sufrida en Venezuela desde los albores constitucionales pone de manifiesto el hecho de que los numerosos textos constitucionales, desde la Carta de 1811, formularon solemnes y minuciosas declaraciones de derechos y garantias para el gobernado, pero no hicieron tanto hincapié en torno a dotar a estos derechos de instrumentos eficaces que aseguraran su respeto por parte de las autoridades, o su restablecimiento para el supuesto de que se hubiera producido su violación. Curiosa resulta la observación de que, si en Venezuela no se instauró desde un primer momento un proceso de amparo, en sentido amplio, como medio de tutela de los derechos y garantías que sus textos constitucionales reconocían al ciudadano, sí, por el contrario, podemos observar cómo ha existido una profunda preocupación por el establecimiento de medios que garantizaran el respeto y cumplimiento del derecho a la libertad y seguridad personales ${ }^{2}$.

El primer antecedente del actual amparo lo podemos observar en la Constitución Federal de 21 de diciembre de 1811, texto que reconocía en su artículo 165:

"La libertad de reclamar cada ciudadano su derecho ante los depositarios de la autoridad pública con la moderación y respeto debido, no podrá impedirse ni limitarse. Todos deberán hallar un remedio pronto y seguro con arreglo a las leyes.... ${ }^{3}$

Otro indicio del nacimiento de los mecanismos orientados a la protección de los derechos en la historia venezolana lo podemos encontrar en el texto constitucional del Estado de Venezuela de 24 de septiembre de 1830, en cuyo artículo 187 establecía que "serán culpables y castigados conforme a la ley quienes expidieren, firmaren, ejecutaren o mandaren ejecutar decretos, órdenes o resoluciones contrarias a la Constitución y leyes que garantizaren los derechos individuales, así como los que las ejecutaren", aunque en ningún momento se procediera al desarrollo legislativo de ese remedio, situación que se va a poner de manifiesto a lo largo del curso constitucional venezolano y que ha producido una ausencia de tutela efectiva de los derechos del ciudadano venezolano hasta tiempos recientes.

1 Las Constituciones de Venezuela, Allan Brewer Carias, Madrid, 1985, Centro de Estudios Constitucionales. Introducción.

2 El primer texto sería la Constitución de 1819.

3 "Estudios sobre la Constitución", Esteban Agudo Freytes, Libro Homenaje a Rafael Caldera, tomo II, UCV, Caracas, 1979, pág. 660. 
Otros dos intentos constitucionales de salvaguardia de los derechos pueden ser estudiados: el primero lo establece el artículo $4 \mathrm{del} \mathrm{De}$ creto de Garantias del General Falcón de 16 de agosto de 1863, al reconocer que "los principios, derechos y garantías reconocidas en los artículos anteriores no podrán ser alterados..." ${ }^{4}$; el segundo puede ser estudiado en el artículo 16 de la Constitución Federal de 22 de abril de 1864, al establecer: "Las leyes del Estado señalarán penas a los infractores de las garantias, y establecerán los trámites para hacerlas efectivas", hecho que, en este caso, tampoco tuvo eficacia práctica ${ }^{5}$.

A partir de la Constitución de 1864, el Estado dictatorial no entiende de romper las fórmulas de la Constitución escrita para establecer en su lugar normas empiricas y simples de los Gobiernos de facto. Por el contrario, simula por ellas, y en todo momento, un casi reverencial respeto, pues que de su observancia no puede resultar la menor limitación a su autoridad, todo lo contrario, pues las modificaciones más importantes que se observan en los textos constitucionales son las relativas al engrandecimiento de la autoridad del gobernante, y para el caso que esto pudiera suceder, la docilidad del Parlamento elimina tales acciones, de ahi las numerosas Constituciones venezolanas desde $1864^{6}$.

La evolución posterior de los textos constitucionales vuelve a hacer, salvo excepciones, referencia al respeto de los derechos por parte de las autoridades, pero sin variar en esencia el contenido de lo reproducido hasta este momento ${ }^{7}$, en los textos posteriores ${ }^{8}$, hasta la aprobación de la Constitución de 16 de julio de 1936.

Con este nuevo texto se inicia un nuevo período constitucional en Venezuela, que se corresponde con las Constituciones del período de transición entre la autocracia y la democracia (1936-1945), cuyos textos inspirarían luego la Constitución de la dictadura militar (1953) y en el cual debe incluirse la Constitución del Estado Democrático y Social de 1947, de corta vigencia, y que seria la base para la vigente Constitución de 1961.

4 Leyes y Decretos reglamentarios de los EE.UU. de Venezuela, Caracas, 1943, tomo VI, pág. 76.

5 Evolución constitucional en nuestra República y otros textos, AmBrosio Oropeza, Caracas, 1985, pág. 99.

6 Ambrosio Oropeza, op. cit., págs. 107 y ss.

7 Las Constituciones de Venezuela, Luis Mariñas Otero, Madrid, 1965, Editorial Cultura Hispánica, pág. 330.

8 Desde la Constitución de 1893 hasta el texto de 1936 existieron 9 cartas fundamentales. 
Las disposiciones contenidas en el artículo 123, ordinal 11, de este texto, establecieron un medio de impugnación ante la Corte Federal y de Casación, que se dirigía en general contra todos los actos del poder público violatorios de la Constitución, lo que abría la puerta a la jurisprudencia del citado Tribunal para proteger a los ciudadanos contra cualquier acto violatorio de la ley, y por tanto de sus derechos, pero esta disposición fue aplicada aisladamente, tratándose de ciertos actos administrativos atentatorios contra los derechos del hombre, y su eficacia fue limitada, sobre todo por falta de una adecuada reglamentación ${ }^{9}$.

Un nuevo intento se produciría en la redacción del Proyecto que serviría de base para la Constitución de 1947, y que trató de incorporar al texto la garantía de amparo con su denominación específica, pero desgraciadamente esta disposición no pasó de los correspondientes debates parlamentarios, limitándose los constituyentes, en sustitución del amparo, a establecer el habeas corpus ${ }^{10}$.

Posteriormente, la Constitución autoritaria de 15 de abril de 1953 significó un claro retroceso respecto de la evolución hasta aquí vista, puesto que, aparte de no hacer ninguna referencia a la protección de los derechos y garantías, eliminaba el habeas corpus, que hasta este momento había sido el único remedio existente para la protección de los derechos, y además otorgó al Presidente de la República facultades exorbitantes para la suspensión de los derechos individuales.

\section{EL AMPARO EN LA CONSTITUCIÓN DE 1961}

Por muchos años el legislador venezolano se conformó con insertar en el texto constitucional una enumeración de los derechos, a los que impropiamente llamaron también garantías, pero, excepción hecha del derecho a la libertad personal, ninguno de estos derechos recibiría una especial protección, dejándose sin sanción inmediata y oportuna el desconocimiento de los mismos ${ }^{11}$.

9 "El amparo en México y Venezuela», Héctor Fix Zamudio, Libro Homenaje a Lorenzo Herrera Mendoza, UCV, vol. 2, pág. 340.

10 Amparo y habeas corpus en la Constitución de 1961, J. A. DE MigueL, Caracas, 1965, págs. 41 y 42 .

1 La Nueva Constitución de 1961, Ambrosio OropezA, Caracas, 1971, pág. 245. 
Ante la necesidad de reformar la Constitución autoritaria de 1953, que había supuesto una marcha atrás en el funcionamiento democrático de la República, se creó en el seno del Congreso una Comisión bicameral de reforma constitucional ${ }^{12}$, que inició una serie de estudios preparatorios de lo que después sería la Constitución de 1961, y que supondría el inicio de una nueva etapa constitucional, caracterizada por la configuración del Estado venezolano como un Estado democrático ${ }^{13}$.

Tras los debates parlamentarios de que fue objeto, el Proyecto de Reforma de la Constitución fue aprobado, y de esta manera nacia una nueva Constitución, en cuya Exposición de Motivos reconocía que nacía con "el propósito de... amparar la dignidad humana, promover el bienestar social y la seguridad personal..., mantener la igualdad social y jurídica, sin discriminación..., sustentar el orden democrático como único e irrenunciable medio de asegurar los derechos y dignidad de los ciudadanos, y favorecer pacíficamente su extensión a todos los pueblos de la tierra".

ESTEBAN AGUDO FREITES ${ }^{14}$ nos indica cómo al iniciarse en 1960 el estudio del Proyecto de Reforma de la Constitución, un clima de armonía preside el Congreso que dicta el texto constitucional, y ese ambiente de transacción y conciliación de ideas, con el fin de promulgar una Constitución que suponga el retorno a la legalidad, unido a una intención nacida en contra del menosprecio hacia el libre goce y ejercicio de los derechos y libertades, es lo que hizo posible que los constituyentes dirigieran sus pensamientos hacia la creación de medios eficaces para la garantía de los mismos. De esta manera la nueva Carta consagraba dos acciones o recursos dirigidos a asegurar la efectividad de los derechos fundamentales: el amparo y el habeas corpus.

El primero se configura como un remedio destinado a proteger los derechos enumerados en el Título III, sin olvidar aquellos otros derechos que, siendo inherentes al ser humano, no están regulados en la Constitución, tal y como afirma el artículo 50:

12 El texto que se tomó como base fue el de 1947.

13 Las discusiones sobre el amparo se pueden consultar en las Actas 5, 16, 17,49 y 50 .

${ }_{14}$ "Estado actual del amparo en Venezuela", Esteban Agudo F., Libro Homenaje a Rafael Caldera, UCV, Caracas, 1979, pág. 682. 
"La enunciación de los derechos y garantías contenidas en esta Constitución, no debe entenderse como negación de otros que, siendo inherentes a la persona humana, no figuren expresamente en ella.

La falta de ley reglamentaria de estos derechos no menoscaba el ejercicio de los mismos."

Del amparo quedaría excluido el derecho a la libertad personal, que sería regulado en un procedimiento de habeas corpus que recoge, con carácter transitorio, y hasta que no se regule mediante la correspondiente ley de amparo, a que se refiere el artículo 49, la Disposición Transitoria Quinta.

Sobre el amparo, la Constitución no contiene, como en el caso del habeas corpus, ningún dispositivo reglamentario. El constituyente acogió tímidamente la institución; más que acogerla, "prometió gestionar su acogida en el artículo 49, pues dejó a una ley posterior su regulación” "15, a pesar de que, durante el proceso constituyente, una fracción parlamentaria solicitó a un sector de la doctrina, encabezado por J. A. DE MIGUEL, la redacción de unas bases que pudieran, a groso modo, regular constitucionalmente el amparo ${ }^{16}$.

La Constitución venezolana de 1961 no reguló el amparo, hecho que, como más adelante tendremos ocasión de ver, hubiera evitado los enfrentamientos doctrinales y jurisprudenciales que se producirían con posterioridad, pero en favor de este Texto constitucional debemos afirmar que fue determinante y decisivo para que se pensara en la necesidad de establecer un mecanismo interno, específico y directo, que sirviera de defensa a los derechos fundamentales, tal y como queda reflejado en el artículo 49:

"Los tribunales ampararán a todo habitante de la República en el goce y ejercicio de los derechos y garantías que esta Constitución establece, en conformidad con la ley.

El procedimiento será breve y sumario, y el juez competente tendrá potestad para restablecer inmediatamente la situación jurídica infringida."

15 J. A. DE MigueL, op. cit., pág. 43. titucionales".

${ }^{16}$ Bajo el nombre de "La institución de amparo, motivación y bases cons- 


\section{EVOLUCIÓN DEL AMPARO HASTA LA PROMULGACIÓN DE LA LEY ORGÁNICA DE AMPARO}

\section{Confusiones doctrinales y jurisprudenciales}

La nueva Constitución venezolana incorporó en su articulado la acción de amparo dirigida a la tutela de los derechos fundamentales, y no se limitó a regular la defensa del derecho a la libertad personal, como habian hecho los anteriores textos constitucionales. No obstante, surgió en la década 1961-1972 ${ }^{17}$ una enorme confusión en la práctica judicial venezolana que llevó a los juristas a iniciar juicios de amparo en defensa de derechos fundamentales, $y$ a los tribunales a pronunciarse en favor o en contra de los mismos, incluso a falta de una regulación específica del amparo.

Tres son las causas que subyacen en esta práctica por parte de los especialistas del Derecho venezolano:

1. El hecho de que los constituyentes regularan el amparo en el artículo 49 del texto demuestra una clara voluntad hacia su inmediata aplicación, aunque la regulación legislativa no se produjera hasta 1988.

2. En la mente de los juristas venezolanos subyacía el deseo de aplicar el amparo de forma similar a como se había producido en Argentina. En este país, la aplicación del amparo, como medio tuitivo de los derechos, se produjo a través de dos pasos muy importantes. El primero mediante la legislación local ${ }^{18}$, lo que derivó en la expedición de numerosas leyes provinciales de amparo. El segundo momento de la evolución del amparo en Argentina debemos referirlo al ámbito nacional, y en este sentido el amparo surgió a través de los tribunales federales, en particular de la Corte Suprema de Justicia, siendo dos los fallos clásicos iniciales: el caso Siri (SCSJA 27-12-1957) y el caso Kot (SCSJA 5-9-1958), casos en los que el argumento sustentado consistió en la necesidad de tutelar de manera rápida los derechos fundamentales que reconocía la Constitución a pesar de la falta de reglamentación ${ }^{19}$.

17 Se menciona como límite de este período de confusión el año 1972, porque fue en este año cuando una sentencia de la Corte Suprema puso fin a esta práctica.

18 Se estableció por primera vez en el artículo 17 de la Constitución de la provincia de Santa Fe de 1921.

19 La protección procesal de los derechos humanos ante las jurisdicciones nacionales, Héctor FIX ZamUdIO, Madrid, 1982, págs. 104 a 111. 
3. La interpretación que se hacía, por parte de los juristas, del artículo 50 de la Constitución para darle vigencia práctica al amparo, pese a su innegable carácter programático ${ }^{20}$.

Hasta la entrada en vigor de la Constitución de 1961, el tema había quedado demasiado claro, pero fue a partir de la promulgación del texto constitucional, y por las causas antes apuntadas, cuando se iniciaron una serie de acciones de amparo, fruto de las confusiones nacidas en base a los artículos 49 y 50 y a la Disposición Transitoria Quinta de la Constitución.

Con fecha 29 de agosto de 1967, el Juzgado accidental número 7 de Primera Instancia del Estado Miranda hacía pública sentencia en virtud de la cual se establecía que "la Constitución, en su artículo 49, ordena a los jueces amparar a todos los habitantes en el goce y ejercicio de todos los derechos y garantías, dando potestad al juez competente para restablecer de forma inmediata la situación jurídica infringida dentro del procedimiento breve y sumario".

La proclamación constitucional del amparo desencadenó la utilización del mismo para la defensa de los derechos. Algunos sectores de la judicatura determinaban en alguna de sus sentencias la necesidad y la obligación que tenían los tribunales de restablecer la situación infringida por actos de autoridad, puesto que, de no ser así, devendría la existencia de un estado absoluto de desamparo frente a los actos arbitrarios de la autoridad, incluso de otros particulares, y la Constitución se convertiría en un simple programa sin eficacia ni vigencia real ${ }^{21}$.

Incluso en algunas sentencias se llegó a determinar que los jueces debían de armarse de valor moral para imponer la vigencia de la Constitución y restablecer las situaciones jurídicas infringidas frente a cualquier autoridad, así como la necesidad de hacer saber al Ejecutivo nacional la urgencia de la promulgación de la ley de amparo ${ }^{22}$.

Estas actuaciones judiciales que habian llegado a aplicar el amparo, aun a falta de una ley que regulara sus fundamentos y funcionalidad, derivaron en una división doctrinal que oscilaba entre las tesis restriccio-

20 Esteban Agudo F., op. cit., pág. 689.

${ }^{21}$ Sentencia de 13 de septiembre de 1969 del Juzgado 4 de Primera Instancia Civil del Estado Miranda.

${ }_{22}$ Sentencia de la Corte Suprema Penal del Distrito Federal de 22 de diciembre de 1969. 
nistas ${ }^{23}$ sobre la utilización del amparo en tanto que no estuviera regulado legislativamente, $y$ aquel otro sector que, con base a lo establecido en el artículo 50, defendían el ejercicio del amparo reconocido en el artículo 49 , aun a falta de rey reguladora ${ }^{24}$.

La indiferencia de los legisladores en regular los preceptos fundamentales de la Constitución de 1961 y la reticencia del Poder Ejecutivo en presentar proyectos sobre dichos preceptos, crearon una situación confusa en la jurisprudencia y en la doctrina, a semejanza y especialmente bajo la influencia de los autores argentinos que expusieron la actividad de la Corte Suprema de la Nación argentina al acoger, después de la caída del Gobierno de Perón, el recurso de habeas corpus con las características del amparo, que no existía en la Constitución vigente.

\section{Restricción jurisprudencial del amparo}

Si bien es cierto que en los casos que hemos tenido ocasión de estudiar, las demandas de amparo fueron aceptadas por algunos jueces y rechazadas por otros, siempre existieron dudas sobre la procedencia de esta institución por parte de los tribunales de apelación, y en particular por la Corte Suprema de Justicia, hasta que, de manera definitiva, la propia Corte, por conducto de la Sala Político-Administrativa, tanto en su sentencia de 14 de diciembre de 1970 como en su acuerdo con fuerza obligatoria de 24 de abril de 1972, estimó que no eran competentes los jueces penales para acordar el juicio de amparo en sentido amplio, ya que ante ellos únicamente puede interponerse el habeas corpus a que hace referencia la Disposición Transitoria Quinta.

Con motivo de las decisiones de la Corte, el ejercicio de la acción de amparo prevista en el artículo 49 fue paralizado hasta tanto se sancionara y promulgara la ley que desarrollase los principios fundamentales de dicha disposición, especialmente la atribución de competencia específica a determinados jueces, produciéndose una situación grave y que suponía ante todo un retroceso, aunque algún sector de la doctrina afir-

${ }^{23}$ Tesis representada por los Doctores Esteban Agudo F., Ambrosio Oropeza y Víctor M. Álvarez, entre otros.

${ }_{24}$ La segunda tesis estaba representada por los Doctores Escala Zerpa, Morris Sierralta, Ramón Quintero, Ramón Escobar Salom, Gilmer Vilora Hernández, José Gabriel Sarmiento, etc. 
maba que el acuerdo de 1972 había atenuado las conclusiones de la sentencia de $1970^{25}$.

Hasta este momento habían sido presentados tres proyectos de Ley de Amparo ${ }^{26}$ en base a la necesidad de acelerar, a tantos años de la vigencia de la Constitución de 1961, el crecimiento de la Constitución, constituyendo un medio para tal aceleración el fortalecimiento de la aplicación de los derechos y garantías, en tanto que éstos procuran una protección del individuo frente al poder del Estado o de otros individuos, $y$ en este cuadro nace la necesidad de hacer sólida la institución del amparo, "pues el amparo es uno de los instrumentos más nobles del derecho constitucionalı ${ }^{27}$, pero, a pesar de la voluntad manifestada por el mundo jurídico venezolano, ninguno de estos proyectos tuvieron una eficacia inmediata, en el sentido de forzar a los poderes nacionales a la regulación legislativa de los preceptos establecidos en la Constitución.

\section{Cambio de criterio de la Corte Suprema: Bases para la admisión de la acción de amparo}

A pesar de la precisión de las disposiciones del Acuerdo de 1972, que negaba competencia específica a los Jueces de Primera Instancia para conocer de acciones de amparo en protección de un derecho subjetivo personal diferente al derecho a la libertad personal, los juzgados siguieron conociendo de acciones de amparo en defensa de las garantías constitucionales ${ }^{28}$, que serian rechazadas, casi en su totalidad, por los tribunales de apelación.

Va a ser en este momento cuando se produjo un hecho que esperanzó a los juristas venezolanos deseosos de una ley que regulara el amparo, como recurso interno y específico de tutela de los derechos que la

pág. 611 .

25 Estado de Derecho y control judicial, Allan B. Carías, INAP, Madrid, 1987,

26 Presentados respectivamente por la Academia de Ciencias Políticas y Sociales, la Procuraduría y la Fiscalía Generales de la República, y el Doctor Ramón Escobar Salom.

${ }^{27}$ El amparo en Venezuela, Ramón Escobar Salom, Caracas, 1971, págs. 14 y ss.

${ }^{28}$ Sentencia del Juzgado 1 de Primera Instancia Civil del Estado Lara de 13 de abril de 1973; Sentencia del Juzgado 1 de Primera Instancia Penal del Estado Lara de 15 de mayo de 1976, y Sentencias 11 de noviembre de 1976 y de 23 de junio de 1977 del mismo Juzgado. 
Constitución regulaba y de aquellos otros que, no regulados constitucionalmente, sean innatos al ser humano.

El Congreso aprobó por ley la Convención Americana de Derechos Humanos en 1977, así como el Pacto Internacional de Derechos económicos, sociales y culturales en 1978 y el Pacto Internacional de Derechos civiles y políticos, en el mismo año, en cuyos textos se establecía la obligación de los Estados partes de garantizar el ejercicio de los derechos humanos y el derecho de toda persona a un recurso sencillo y rápido o a cualquier otro recurso efectivo ante los tribunales competentes que los amparasen contra actos violatorios de los derechos humanos.

Estas disposiciones internacionales, que constituyen ley en Venezuela tras la publicación de tales acuerdos ${ }^{29}$, fueron apreciadas por los tribunales como reguladoras de un derecho de amparo, suponiendo un cambio en la jurisprudencia, puesto que, en base a estos antecedentes, en 1982 comenzó a modificarse la rigidez interpretativa que en materia de amparo se había producido en 1970 y $19722^{30}$.

La Corte Suprema, mediante sentencia de 20 de octubre de 1983 , comenzó por admitir la posibilidad del ejercicio de acciones de amparo de derechos distintos al recurso de habeas corpus, al señalar, respecto del artículo 49 de la Constitución, que ula norma ha sido objeto de divergente interpretación por parte de la doctrina y de la jurisprudencia, pues mientras unos consideraban que se trata de una norma programática cuya aplicación queda diferida hasta que se dicte la ley especial que regule la materia, otros estiman que la ausencia de este instrumento legal no impide el ejercicio del recurso... considera la Corte que con la declaración del artículo 49 , los constituyentes han reformado su voluntad en el sentido de mantener la integridad de los derechos humanos y ponerlos a cubierto de cualquier intento o acto que pudiera vulnerarlos" ${ }^{31}$.

En todo caso, la Corte advirtió sobre el ejercicio del recurso de amparo en el sentido de "que al admitir la posibilidad del ejercicio actual del amparo, no puede la Corte dejar de advertir que los tribunales deben ha-

29 Gacetas oficiales 31.256, de 14 de junio de 1977, y Gaceta extraordinaria 2.146, de 18 de enero de 1978.

30 Sentencia del Juzgado 4 de Primera Instancia Civil del Distrito Federal de 24 de noviembre de 1982, ratificada por el Juzgado Superior 8 de lo Civil y Mercantil del Distrito Federal.

31 "Plena Vigencia del Recurso de Amparo", RenÉ DE Sola, Revista del Consejo de Judicatura, año VIII, n.ำ 31, Caracas, 1983, págs. 169 a 172. 
cer un uso prudente y racional de la norma constitucional, tratando de suplir mediante la analogía y demás instrumentos de interpretación, la lamentable ausencia de una ley reguladora de la materia».

En base a estos antecedentes, en el año 1985 fueron presentados ante la Cámara de Diputados del Congreso venezolano dos Proyectos de ley, que fueron decisivos para la regulación legislativa del artículo 49. EI primero de ellos, elaborado por COPEI (Partido Socialcristiano), sería presentado ante la Comisión de Política Interior de la Cámara de Diputados el 28 de marzo de 1985, mientras que el segundo, presentado tres meses más tarde, sería presentado mediante el sistema de iniciativa legislativa popular ${ }^{32}$.

Estos proyectos, junto a los antecedentes antes estudiados, sirvieron de base a los debates parlamentarios que se iniciarian a finales de 1987, con el fin de suplir la falta de una ley reguladora del amparo; no obstante, la falta de esta ley había hecho que la jurisprudencia fuera perfilando los caracteres propios del amparo y los del juicio a través de los cuales se le promoviera, mediante principios y criterios jurisprudenciales orientadores, apoyados por calificados comentarios doctrinales sobre la materia $^{33}$.

\section{LA LEY ORGÁNICA DE AMPARO ANTE EL CONGRESO VENEZOLANO}

La Comisión de Política Interior de la Cámara de Diputados recibía, con fecha 28 de marzo de 1985, y mediante remisión de su Presidente, el Proyecto de "Ley de Amparo sobre Derechos y Garantías Constitucionales" promovido por COPEI, procediéndose a iniciar el estudio del correspondiente articulado. En fecha 19 de junio de ese mismo año, y por remisión igual a la anterior, la Comisión recibía un nuevo Proyecto, denominado "Ley de Amparo de los derechos constitucionales y derechos inherentes a la persona humana», acumulándose ambos, por tratarse de materia análoga, a los fines de su estudio por parte de la Comisión.

32 Regulado en el artículo 165.5 de la Constitución, según el cual la iniciativa de las leyes puede corresponderle a un número no menor de 20.000 electores debidamente identificados.

${ }^{33}$ "Exposición de Motivos del Proyecto", Argenis Riera Encinoza. Sumario sobre la LOA, Caracas, 1988, págs. 156 y ss. 


\section{El proceso de formación}

A los efectos del proceso de formación de la ley respectiva, se procedió a integrar, en el seno de la Comisión encargada del estudio, una Subcomisión de Ponencia integrada por el Diputado David Morales Bello, en su carácter de la Comisión, siendo incorporados al respectivo equipo los Doctores Orlando Tovar Tamayo y Hernán Escarrá Malavé, a los efectos de incluir sus aportes a los estudios que permitieran fijar posición respecto a los Proyectos antes especificados. En virtud de ofrecer ambos aspectos coincidentes, aunque diferenciándose en algunas de sus previsiones, se acordó proceder a redactar una síntesis que conjugara las partes aceptadas por la Subcomisión de Ponencia, con otras normas añadidas en razón del estudio realizado.

Paralelamente al análisis pormenorizado de la materia sometida a su consideración, se procedió a solicitar opiniones de instituciones calificadas, magistrados judiciales, profesores universitarios, funcionarios públicos y personalidades privadas de quienes era presumible obtener puntos de vista que ilustraran, en la forma más amplia, la tarea de hacer la ley, organizándose, al mismo tiempo, un catálogo jurisprudencial que sirviera de ayuda para llevar a la letra de la ley aquellas experiencias provenientes del funcionamiento del Poder Judicial del país. De manera especial se tomó en consideración el Proyecto redactado en 1971 por el Doctor Ramón Escobar, así como los redactados por la Comisión Procuraduría-Fiscalía General de la República y el de la Academia de Ciencias Políticas y Sociales, y el trabajo elaborado por el Magistrado René Paz Brual ${ }^{34}$.

El resultado de los criterios aportados, de las entrevistas realizadas, de los foros efectuados, tanto entre los sectores universitarios como judiciales, así como el estudio de la amplia doctrina, tanto nacional como internacional, existente en materia de amparo constitucional, fue la redacción de un Proyecto denominado "Ley Orgánica de Amparo sobre derechos y garantías constitucionales".

A finales de 1987 se presentaba ante la Cámara de Diputados un Proyecto de ley que regulaba la figura del amparo, que tras los debates

34 Los Derechos Humanos y el Amparo constitucional, RenÉ PAz BruAL, Estudios Jurídicos del Estado Lara-Colegio de Abogados del Estado Lara, Barquisimeto, 1987. 
parlamentarios ${ }^{35}$, y debido al enorme consenso politico que reinó en los mismos ${ }^{36}$, entraría en vigor el día 22 de enero de 1988.

\section{Condicionamientos ideológicos de la regulación del amparo}

Llegados a este momento cabría preguntarnos cuáles fueron los condicionamientos necesarios para la regulación del amparo, veintisiete años después de que los constituyentes decidieran plasmarla programáticamente en el texto constitucional. ¿Hasta qué punto ha cambiado la situación política en la República Venezolana? ¿Cuáles han sido las circunstancias que han llevado a los legisladores a la regulación jurídica del amparo?

En el fondo se deduce, no tanto una modificación total y radical de la situación político-jurídica venezolana, por cuanto los rasgos que definen la nueva configuración de la República quedaban claramente plasmados a lo largo de todo el texto constitucional, pero sí una serie de problemas interpretativos, que suponían un retroceso en la definición jurídica que el nuevo texto de 1961 había otorgado al Estado venezolano. Entre las circunstancias que empujaron a los legisladores a plantear la necesidad de una ley que reglamentase definitivamente el amparo, podemos encontrar:

1. La orientación e inspiración de la actuación del Estado hacia la justicia social constituye un signo inequívoco de la prefiguración de ese nuevo Estado social y democrático de Derecho como una superación de la arquitectura dogmática del reconocimiento de los derechos individuales solamente, y la necesidad de protegerlos.

2. En una democracia pluralista y dinámica no puede concebirse una Constitución que pueda permanecer aprisionada. Todo el cuerpo de leyes esenciales del Estado debe obedecer a la fecundidad de sus fines, $y$ entre éstos se encuentra el libre desarrollo y ejercicio de los derechos por ella reconocidos.

35 Los debates parlamentarios pueden ser consultados en los Diarios de Debates de la Cámara de Diputados números 68, 70, 72, 85 y 86, y en los Diarios de Debates del Senado números 81,83 y 93.

${ }_{36}$ El consenso había sido obtenido con anterioridad por parte de las fracciones de AD (Acción Democrática), COPEI (Partido Socialcristiano) y la Fracción del Movimiento Electoral del Pueblo, que contaron con el apoyo del MAS (Partido Comunista), que constituyen una amplia mayoría del número de representantes. 
3. La incorporación de Venezuela al elenco de los países contemporáneos que materializan en el ordenamiento jurídico positivo el pleno goce de los derechos, determina el desarrollo, mediante ley, de la normativa constitucional consagratoria del amparo a los fines de hacer ejercitables las previsiones encaminadas a no dejar en el vacío la materialización del régimen de derechos y garantías.

4. La ausencia de ley implicaba riesgos, y la inexistencia de un marco legal para desarrollar las disposiciones constitucionales trajo consigo algunas decisiones cuestionadas por parte de tribunales de justicia, que recordaban día a dia la necesidad de esta regulación.

5. La misma Corte Suprema, fundamentándose en los Convenios Internacionales aprobados por Venezuela en relación a los derechos humanos $y$ al amparo, y fundamentándose igualmente en el artículo 50 de la Carta Fundamental, cambió de criterio a partir de la sentencia de 20 de octubre de 1983, negando la condición de norma programática al artículo 49 y reconociéndole la condición de norma vinculante. Con este paso, la Corte estableció la obligatoriedad de aplicación del artículo 49 de la Constitución $y$, al admitirse la posibilidad de ejercicio del recurso de amparo, se advierte a los tribunales de la necesidad de resolver cuanto caso se planteara.

6. El consenso otorgado por todas las fracciones políticas que estaban representadas en el Congreso, quienes al margen de divergencias interpretativas, evidenciaban la necesidad de romper las situaciones de antijuridicidad y transgresiones que se estaban infringiendo a los derechos fundamentales, amparadas bajo el argumento de la falta de una ley reguladora del amparo.

En definitiva, podemos observar tres fuentes de inspiración de esta Ley; el precepto dogmático de la Constitución, contenido en los artículos 49 y 50; la jurisprudencia dictada a diversos niveles por los tribunales de la República, y la doctrina de los publicistas patrios; los antecedentes de otros Proyectos y Anteproyectos e iniciativas, y el clamor de su formulación por la sociedad como necesidad de cumplir el mandato de desarrollar un cuerpo de leyes que ampare, proteja y defienda, mediante un medio judicial idóneo, los derechos y garantías de la persona humana. 


\section{Propósito y estructura de la Ley Orgánica de Amparo *}

El propósito fundamental de esta Ley orgánica fue regular el artículo 49 de la Constitución, siendo plausible su promulgación por cuanto, de una vez por todas, inscribe dentro del ordenamiento jurídico venezolano una ley que regula la norma básica de la Constitución. Además, señalará a la jurisprudencia el camino a seguir en beneficio de cualquier persona que vea amenazados sus derechos y garantías constitucionales por las instancias del Poder Público. Los jueces dispondrán de un procedimiento idóneo, seguro y concreto, regulado y normalizado, y ante todo, se terminaba con la larga polémica doctrinal y jurisprudencial, pudiendo considerarse como la ley más importante dictada en el país, después de la propia Constitución ${ }^{37}$.

Debemos partir de la consideración de que el amparo constitucional parte de la existencia de una laceración jurídica y, como instrumento de tutela y salvaguardia de los derechos de la persona humana, garantiza que nadie salga lastimado por el ejercicio del poder o por la conducta de los particulares, teniendo como razón de ser la preservación de la libertad como valor en el cual se fundamenta la dignidad del hombre.

La Ley de Amparo, cuidadosamente redactada para lograr claridad en la intención y nitidez en la expresión, consta de 49 artículos que se distribuyen en 5 Títulos de la forma siguiente:

El Título I comprende las disposiciones generales a través de las cuales se determinan los derechos protegidos y se consagra la acción destinada a su protección, extendiéndose desde el artículo 1 al 5.

El Título II está dedicado a establecer la condiciones de admisibilidad de la acción de amparo y comprende el artículo 6 , integrado por 8 parágrafos.

El Título III trata con exclusividad la materia de la atribución de competencia de los jueces y extiende la temática procesal de la competencia múltiple, de conformidad con la evolución de la jurisprudencia en su más alto nivel de la República, estableciéndose las pautas procedimentales atinentes "de acuerdo con la afinidad que con su competencia natural tengan los derechos violados". Este título, que está integrado por los artículos 7 al 12, sería objeto de reforma ${ }^{38}$ por parte del Congreso, co-

* El contenido y significación de la Ley Orgánica de Amparo será tratado en un segundo estudio que seguirá al presente.

37 La ley de Amparo, Allan Brewer Carías, Caracas, 1988, pág.12.

38 Reforma Parcial de Ley Orgánica de Amparo sobre Derechos y garantías constitucionales de fecha 27 de septiembre de 1988, publicada en Gaceta Oficial, número 34.060 . 
mo consecuencia de la observación de acontecimientos surgidos con motivo de acciones de amparo ejercidas por particulares ante tribunales de la jurisdicción ordinaria, en relación con decisiones adoptadas por el Consejo Supremo electoral, y mediante revisión del articulado que integra dicha ley, con el interés institucional de centralizar en un órgano del Poder Judicial de jerarquía nacional suficiente la facultad de decidir acerca de las solicitudes de amparo referidas a los derechos políticos relacionados con las resoluciones adoptadas por los organismos electorales del país ${ }^{39}$.

El Título IV traza el cauce procesal del desarrollo de la acción. Se extiende desde el artículo 13 al 37 y comprende los aspectos formales $y$ requisitos exigidos para la procedencia de la protección judicial en relación a la capacidad de las personas físicas y juridicas para intentar la acción, quedando a salvo las atribuciones que corresponden al Ministerio Fiscal y a la Procuraduría de Menores. Se califica la acción como de orden público, se establecen la gratuidad y la potestad del juez para obtener la evacuación de pruebas, especificándose los requisitos esenciales a cumplirse por el quejoso en la solicitud judicial, como también normas tendentes a regular las solicitudes dudosas con ausencia de requisitos. Se incluyen sanciones para los jueces por suscitar conflictos de competencia infundados $y$ se consagra el principio de igualdad de partes, excluyéndose los privilegios.

Se amplía la potestad discrecional de los jueces, eliminándose al mismo tiempo las formas voluntarias de autocomposición procesal, previniéndose sanciones para el desistimiento malicioso. Se establece la forma oral y pública para los informes de las partes y un término muy breve para dictar el mandamiento de amparo constitucional. También se sanciona la temeridad manifiesta en la solicitud del quejoso y se incluye una norma general referida al acatamiento del amparo por todas las autoridades, siendo de destacar la imposición de pena para quienes incumplan el mandamiento. Este Título se cierra con normas relacionadas con la sentencia y las responsabilidades derivadas de ellas.

El Título $V$, último del articulado, recoge la normativa del amparo de la libertad y seguridad personales. Ocupa el habeas corpus constitucional y se surte, esencialmente, de la Disposición Transitoria constitucional Quinta, robustecida por la reiterada jurisprudencia de los Tribunales de Instancia y de la Corte Suprema de Justicia.

39 Diario de Debates de la Cámara de Diputados, n. 63,14 de septiembre de 1988 . 